Part of Journal of Research of the National Bureau of Standards, Volume 26, January 1941

\title{
COMBINATION OF SILK FIBROIN WITH ACID AND WITH BASE
}

\author{
By Leland F. Gleysteen and Milton Harris ${ }^{1}$
}

\begin{abstract}
A study was made of the dependence on $\mathrm{pH}$ of the amounts of hydrochloric acid and of potassium hydroxide that are taken up by silk fibroin at $0^{\circ} \mathrm{C}$. The effect of added potassium chloride on this dependence was also investigated, and was shown to be the binding of an increased quantity of acid or base at a given $\mathrm{pH}$.

The maximum acid-combining capacity of silk fibroin is 0.13 milliequivalent per gram; the maximum base-binding capacity is greater than 0.90 milliequivalent per gram. The presence of 0.13 to 0.17 milliequivalent of free carboxyl groups in silk fibroin is estimated from the titration curve. The great amount of base bound can be accounted for only if the phenolic hydroxyl groups of tyrosine take part in the equilibria with base. Further evidence that these groups bind base is provided by the greatly decreased amount of base bound by methylated fibroin.
\end{abstract}

\section{CONTENTS}

I. Introduction

II. Experimental procedure

1. Materials _._. 72

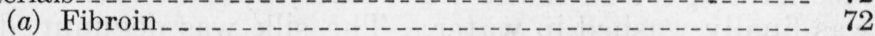

2. Methods Methylated fibroin

(a) Correction for ash $\ldots \ldots \ldots \ldots$

(b) Determination of moisture

(c) Correction for sorption of water

(d) Titration with acid

(e) Titration with base

(f) Determination of $\mathrm{pH} \ldots \ldots \ldots$

(g) Temperature control_._.

III. Results and discussion _...

IV. References

\section{INTRODUCTION}

Many of the chemical and physical properties of a protein fiber are intimately related to the number and arrangement of those groups which bind acid or base. A study of the combination of acid and of base with silk fibroin was therefore undertaken as part of an extensive program for the investigation of the acidic and basic nature of textile fibers.

The manner in which the titration curves of the insoluble proteins, and especially of wool, differ from those of the soluble proteins has been discussed by Speakman and Hirst [1], ${ }^{2}$ by Lloyd and Bidder [2]

1 Research Associates at the National Bureau of Standards, representing the Textile Foundation.
2 Figures in brackets indicate the literature references at the end of this paper. 
and, more recently, by Steinhardt and Harris [3]. The titration of silk fibroin is, in some respects, similar to the titration of wool, but differs in other respects because of decided differences in the number and kinds of constituent amino acid residues. The published analyses of silk [4] indicate that fibroin contains relatively small quantities of the dibasic amino acids arginine, lysine, and histidine, all of which would be expected to bind acid, and an appreciable quantity of one diacidic amino acid, tyrosine, which would be expected to bind base unless its phenolic hydroxyl group is blocked in some way.

The data for proteins do not provide an unequivocal indication of the availability of the hydroxyl groups of tyrosine for binding base. Recent work, however, on the reaction of diazomethane with silk and a number of other proteins indicates that the hydroxyl groups of tyrosine in these substances are probably free.

The relatively high content of tyrosine in fibroin made it seem probable that the role of the hydroxyl groups in acid-base equilibria would be revealed by consideration of the titration data. Since the methylation of these groups can now be readily brought about [5], a comparison of the titration curves of untreated and of methylated fibroin should indicate even more clearly the part taken by the phenolic hydroxyl groups in the binding of base by fibroin.

\section{EXPERIMENTAL PROCEDURE}

\section{MATERIALS}

(a) FIBROIN

Raw, white, Japanese silk which had not been previously treated except for the reeling operation was extracted for 48 hours with alcohol and for 24 hours with ether, both at room temperature, and was finally washed in water. The silk was degummed by treatment with a commercial enzyme preparation, Enzo. ${ }^{3}$ The degumming bath contained $5 \mathrm{~g}$ of Enzo per liter and was maintained at a temperature of $65^{\circ} \mathrm{C}$. The ratio of silk to solution was about 1:40. Each lot of silk was given three consecutive treatments of half an hour each with constant agitation; after each treatment the silk was quickly rinsed in boiling water and was then thoroughly washed in water at room temperature. In order to assure complete degumming, it was found necessary to prevent the silk from becoming tightly matted. Determinations of loss of weight showed that three treatments of half an hour each, and subsequent washings were sufficient to bring the material to constant weight. The loss of weight on degumming corresponded to the loss reported by Rutherford and Harris [6] for silk of the same lot degummed by boiling in soap solutions.

\section{(b) METHYLATED FIBROIN}

Fibroin was methylated with diazomethane as described by Rutherford, Patterson, and Harris [5]. Analysis of the samples for tyrosine by the method of Lugg [7] showed that the tyrosine content

${ }^{3}$ Thanks are due the Wallerstein Laboratories, New York, N. Y., for the enzyme preparation used in this work. 
had been reduced from 12.0 to 2.3 percent, and analysis for methoxyl groups by the method of Vieböch and Brecker [8] showed that the methoxyl content was 2.37 percent.

\section{METHODS}

(a) CORRECTION FOR ASH

The degummed silk contained some base, already bound, and yields an alkaline ash. This alkali affects the extent to which acid or base is sorbed from the solution by the fibroin. The hydrogen-ion equivalence of the ash was determined by an electrodialytic method which has been described elsewhere [9]. The degummed and washed fibroin had an ash content of the order of 0.1 milliequivalent per gram $(M-\mathrm{eq} / \mathrm{g})$. In order to reduce the ash content to a lower value the fibroin was electrodialyzed for 24 hours. By this means, the hydrogen-ion equivalence of the ash was reduced to 0.01 to 0.02 $M$-eq/g. The titration data were corrected for the effect of this residual ash by subtracting the hydrogen-ion equivalence of the ash from the experimentally determined quantity of acid bound or by adding it to the quantity of base bound.

\section{(b) DETERMINATION OF MOISTURE}

All the samples were conditioned at $21^{\circ} \mathrm{C}$ and 65 -percent relative humidity before weighing. The moisture content of the fibers was determined by drying representative samples for 2 hours in a vacuum oven at $105^{\circ} \mathrm{C}$. All titration data in this paper are expressed as milliequivalents of acid or of base per gram of dry fibroin.

\section{(c) CORRECTION FOR SORPTION OF WATER}

In the determination of the titration curves of hygroscopic fibrous materials some investigators have considered the total moisture content of the sample of fibers, at the moment immediately preceding immersion in the solution, as a quantity which should be added to the free water of the system. That is to say, all the water in the system, including that introduced in the fiber phase, has sometimes been regarded as being available for dilution of the solute. However, many workers have recognized, on the basis of direct experimental evidence, that the concentration of an aqueous solution of a solute which is not bound to the fiber by strong chemical or physical forces is increased when a sample of fibers of low moisture content is introduced into the solution. Presumably such an increase in the concentration of the solution is due to the selective sorption of water by the fibers. It is also assumed that such sorption effects occur in solutions of acids and bases and decrease the quantity of water that is available for dilution of the acid or base. Since the acid and base binding capacities, as determined in the present investigation, are calculated from changes of titer, and since the change in the titer of the solutions will depend upon the selective sorption of water as well as upon the quantity of acid or base bound, a correction must be applied for the sorption of water.

The manner of applying this correction term is discussed in detail by Sookne and Harris [10]. In the present investigation the extent of selective sorption of water was investigated by a polarimetric 
method. The highly optically active disaccharide trehalose was used as a reference substance. It was assumed that the trehalose was not sorbed by the fiber. A weighed quantity, $5 \mathrm{~g}$, of fibroin of known moisture content was immersed in the smallest convenient volume, $60 \mathrm{ml}$, of trehalose solution, which was $0.05 \mathrm{~N}$ with respect to hydrochloric acid, and then placed in the constant temperature bath at $0^{\circ}$ C. After 24 hours, aliquots were withdrawn from the stock solution and from the solution in equilibrium with the fibers, and the rotations were measured in a saccharimeter at $20^{\circ} \mathrm{C}$. The rotations of the original and of the final solutions were compared, and the difference was interpreted as a measure of the increase of the concentration of the solution with respect to trehalose, which resulted from the sorption of water by the fibroin. The mean result for a pair of duplicate determinations is shown in table 1.

TABLE 1.-Selective sorption of water by silk fibroin

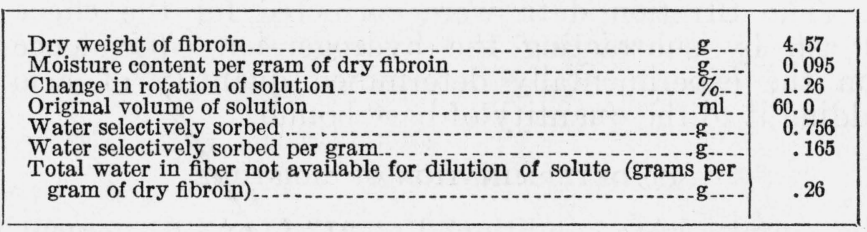

(d) TITRATION WITH ACID

Samples of fibrón weighing either 3.00 or $4.00 \mathrm{~g}$ and containing about 9.2 percent of moisture were placed in $100-\mathrm{ml}$ portions of acid solutions at $0^{\circ} \mathrm{C}$. The solutions contained either varying amounts of hydrochloric acid alone or varying amounts of potassium chloride and hydrochloric acid so adjusted as to bring the total ionic strength, at equilibrium, to $0.2 \mathrm{M}$. Aliquots of the original solutions and of the solutions which had come to equilibrium with the fibroin were titrated with standard sodium hydroxide solutions, using bromcresol purple as the indicator. The change in titer, together with the dry weight of the sample and the correction for selective sorption of water, permits the calculation of the quantity of acid bound per gram of dry fibroin.

To determine whether sufficient time had been allowed for the attainment of equilibrium and whether appreciable acid hydrolysis had occurred, aliquots were withdrawn from the acid solutions which had been in contact with the fibroin for periods of 2,3 , and 4 days. The results indicate that equilibrium is attained within 48 hours and that no appreciable hydrolysis occurs within 4 days at $0^{\circ} \mathrm{C}$ in solutions up to $0.1 N$ with respect to hydrochloric acid.

\section{(e) TITRATION WITH BASE}

Titrations with base were carried out in a manner analogous to the method used for acid titrations, with the addition of precautions to prevent errors resulting from exposure of the solutions to atmospheres containing carbon dioxide. The alkaline solutions were made up from a stock solution of potassium hydroxide of very low carbonate content and a stock solution of potassium chloride of very low carbon dioxide content, by dilution with freshly boiled distilled water. 
To determine the time required to attain equilibrium and to investigate the question of the alkaline hydrolysis of the protein material, a number of samples were immersed in potassium hydroxide solutions at $\mathrm{pH} 12$ for various periods ${ }^{2}$ of time. The results indicate that equilibrium is attained in about 24 hours at $0^{\circ} \mathrm{C}$ and that no appreciable hydrolysis seems to have occurred within 72 hours at this temperature, as the quantity of base bound reached a constant value and the Nessler test did not reveal the presence of any nitrogen in solution. In all subsequent experiments the samples were allowed to remain in the solution for 48 hours before aliquots were withdrawn for titration.

\section{(f) DETERMINATION OF $\mathrm{pH}$}

The $\mathrm{pH}$ values of the solutions were determined with a glass electrode following the method used by Steinhardt and Harris [3].

\section{(g) TEMPERATURE CONTROL}

The solutions were maintained at a temperature of $0^{\circ} \mathrm{C}$ by immersion in a refrigerated bath containing water and ice.

\section{RESULTS AND DISCUSSION}

The amounts of hydrochloric acid and of potassium hydroxide bound by fibroin at $0^{\circ} \mathrm{C}$ at different $\mathrm{pH}$ values (at equilibrium) are given in table 2 and are shown graphically in figure 1 . The titration

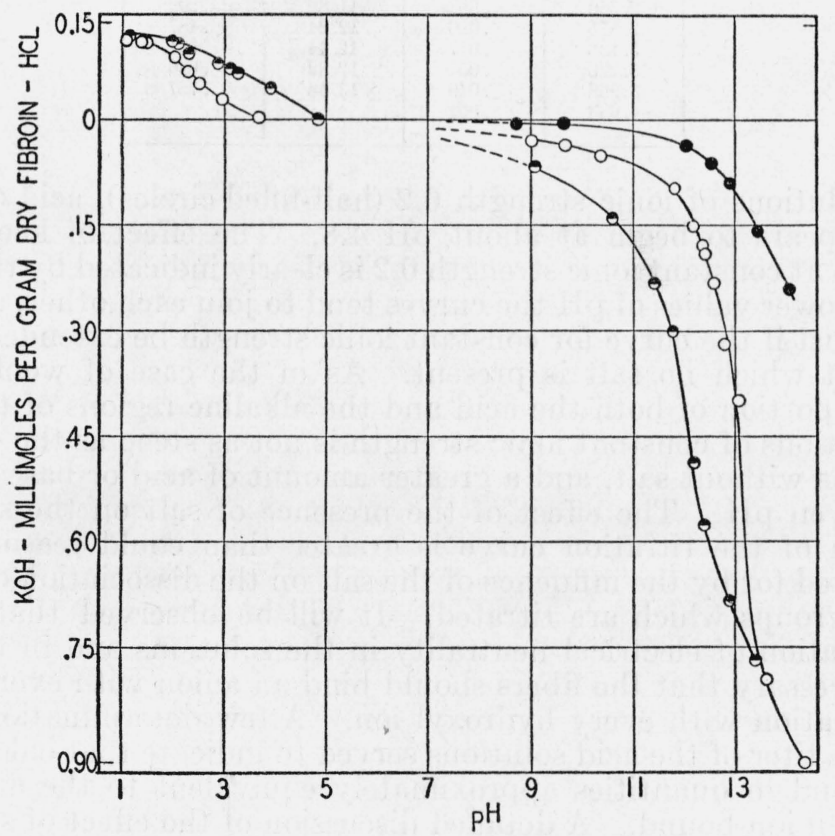

Figure 1.-Combination of silk fibroin with hydrochloric acid and potassium hydroxide as a function of $p H$

O No salt.

Ionic strength $0.2 \mathrm{M}$.

Methylated fibroin, no salt. 
curve for hydrochloric acid in the absence of salt (open circles) drops steeply from a maximum of about $0.13 \mathrm{M}$-eq/g near $\mathrm{pH} 1$ and appears to reach the base line at about $\mathrm{pH} 3.9$. It should be noted that, because of the shallow slope of the curve as it approaches the base line, any error in the ash correction or in the titration data will affect the position of the point at which combination with acid appears to begin.

TABLE 2.-Amounts of acid and base bound by silk fibroin at $0^{\circ} \mathrm{C}$

\begin{tabular}{|c|c|c|c|}
\hline $\mathrm{pH}$ & $\begin{array}{c}\text { Acid } \\
\text { bound }\end{array}$ & $\mathrm{pH}$ & $\begin{array}{c}\text { Base } \\
\text { bound }\end{array}$ \\
\hline \multicolumn{4}{|c|}{ NO SALT PRESENT } \\
\hline $\begin{array}{l}1.083 \\
1.131 \\
1.553 \\
2.046 \\
2.331 \\
2.468 \\
2.950 \\
3.522\end{array}$ & $\begin{array}{c}M-e q / g \\
0.132 \\
.130 \\
.117 \\
.091 \\
.074 \\
.044 \\
.031 \\
.003\end{array}$ & $\begin{array}{r}9.01 \\
9.63 \\
10.40 \\
12.18 \\
12.43 \\
12.76 \\
13.10 \\
13.61 \\
14.25\end{array}$ & $\begin{array}{c}M-e g / g \\
0.033 \\
.034 \\
.052 \\
.147 \\
.205 \\
.314 \\
.395 \\
.798 \\
.904\end{array}$ \\
\hline \multicolumn{4}{|c|}{ IONIC STRENGTH 0.20} \\
\hline $\begin{array}{l}1.187 \\
1.822 \\
2.101 \\
2.360 \\
2.875 \\
3.138 \\
3.276 \\
3.968 \\
4.633\end{array}$ & $\begin{array}{r}0.136 \\
.119 \\
.115 \\
.092 \\
.080 \\
.077 \\
.057 \\
.049 \\
.001\end{array}$ & $\begin{array}{r}9.10 \\
10.61 \\
11.44 \\
11.80 \\
12.24 \\
12.44 \\
12.89 \\
13.48\end{array}$ & $\begin{array}{r}0.070 \\
.139 \\
.228 \\
.298 \\
.487 \\
.581 \\
.686 \\
.767\end{array}$ \\
\hline
\end{tabular}

In solutions of ionic strength 0.2 (half-filled circles), acid combination appears to begin at about $\mathrm{pH}$ 4.8. The effect of keeping the solution at constant ionic strength 0.2 is clearly indicated by the figure. At the lower values of $\mathrm{pH}$ the curves tend to join each other, as indeed they must if the curve for constant ionic strength be extended to that point at which no salt is present. As in the case of wool [3], the central portion of both the acid and the alkaline regions of the curve for solutions of constant ionic strength is not as steep as the curve for solutions without salt, and a greater amount of acid or base is bound at a given $\mathrm{pH}$. The effect of the presence of salt on the slope and position of the titration curve is greater than could reasonably be accounted for by the influence of the salt on the dissociation constants of the groups which are titrated. It will be observed that for the preservation of electrical neutrality in the solutions and in the fibers it is necessary that the fibers should bind an anion with every proton and a cation with every hydroxyl ion. A few determinations of the chloride titer of the acid solutions served to indicate that chloride ions are bound in quantities approximately equivalent to the amount of hydrogen ion bound. A detailed discussion of the effect of salt and a theoretical treatment of the titration data for another fibrous protein, wool, have been given elsewhere by Steinhardt and Harris [3], who showed that the quantity of acid bound depends upon the concentra- 
tion of anions as well as on the concentration of hydrogen ions, and that the quantity of base bound similarly depends on the concentration of cations as well as on hydroxyl ions. They explained the direct dependence on anion, or cation, concentration on the basis of the assumption that when the protein combines with hydrogen ions it also forms partially dissociated stoichiometric complexes with anions and when it combines with hydroxyl ions it forms similar complexes with cations. These conclusions now appear to be applicable to silk fibroin as well.

The titration curve for fibroin obtained from these experiments at $0^{\circ} \mathrm{C}$ differs in several respects from that given by Lloyd and Bidder [2]. At the higher concentrations of acid Lloyd and Bidder indicate that rapidly and continuously increasing amounts of acid are bound as $\mathrm{pH}$ decreases, the highest value shown being some $0.3 M$-eq/g at $\mathrm{pH} \mathrm{1;} \mathrm{the} \mathrm{data} \mathrm{of} \mathrm{the} \mathrm{present} \mathrm{investigation} \mathrm{tend} \mathrm{toward} \mathrm{a} \mathrm{maximum}$ of about $0.13 \mathrm{M}$-eq/g in the region of $\mathrm{pH} 1$. This difference cannot be ascribed to the effects of ash because Lloyd and Bidder report an ash content of only 0.02 percent which, on the assumption of an equivalent weight of 40 for the ash, as found in the fibroin used in the present investigation, would amount to about $0.005 M$-eq/g. The discrepancy may be due in part to some decomposition of the fibroin at the higher temperatures at which Lloyd and Bidder worked. The alkaline branches of the curves are less dissimilar and, in this case, at least, a part of the difference may be attributed to a temperature effect. It has been shown that temperature appreciably influences the binding of base by wool but has very little effect on the binding of acid [11].

It is recognized that the acid-and base-combining capacities of proteins may usually be correlated with their contents of diacidic and dibasic amino acids [12]. The published analytical data on the composition of fibroin are given in table $3[4,13]$. The maximum quantity of acid bound by fibroin, $0.13 M$-eq/g, is nearly twice the sum of the reported contents of arginine and lysine. Such a discrepancy is not unexpected, since in the isolation of small quantities of amino acids from protein hydrolysates the analytical results invariably are low.

TABLE 3.-Amino acid composition of fibroin

\begin{tabular}{|c|c|c|}
\hline Amino acid & Percentage & $M$-eq/g \\
\hline $\begin{array}{l}\text { Glycine a } \\
\text { Alanine } \\
\text { Tyrosine } \\
\text { Arginine } \\
\text { Lysine b } \\
\text { Histidine }\end{array}$ & $\begin{array}{r}43.8 \\
26.4 \\
13.2 \\
0.95 \\
.25 \\
.07\end{array}$ & $\begin{array}{l}5.84 \\
2.97 \\
0.73 \\
.055 \\
.018 \\
.005\end{array}$ \\
\hline
\end{tabular}

\footnotetext{
- Reference [4].
}

b Reference [13].

In the literature no values whatever are reported for dicarboxylic acids in silk fibroin. The nature of the titration curve, however, is such as to suggest that dicarboxylic acid residues are probably present. The total amount of acid plus base bound between $\mathrm{pH} 1$ and $\mathrm{pH} 7$ to 8 (in which range the - $\mathrm{COOH}$ groups are known to undergo dissociation), which is not less than 0.13 and may be as much as 0.17 
$M$-eq/g in the case of silk fibroin, may be regarded as a measure of the total number of free carboxyl groups in the protein. Previous evidence that silk fibroin contains free carboxyl groups was given by Rutherford, Patterson, and Harris [5], who infer the presence of about $0.2 M$-eq/g of free carboxyl groups in the untreated fibroin from the analyses of methylated fibroin for unmethylated tyrosine and for methoxyl groups. The latter estimate lends support to the interpretation of the quantity of acid plus base bound between $\mathrm{pH} 1$ and 8 as representing the free carboxyl content of fibroin.

The amount of base bound in the strongly alkaline region, that is at $\mathrm{pH}$ greater than 11, greatly exceeds the content of free carboxyl groups and can be accounted for only by postulating that the phenolic groups of the tyrosine take part in the binding of base. This result is not unexpected, as Rutherford, Patterson, and Harris [5] concluded, on the basis of their study of the methylation of fibroin with diazomethane, that the hydroxyl groups are free. The greatest amount of base bound in the range covered by this investigation, $0.90 \mathrm{M}$-eq/g, is somewhat more than the tyrosine alone would account for and is, fortuitously, equal to the tyrosine content plus the estimated content of free carboxyl groups. Presumably higher amounts of base would be bound at higher $\mathrm{pH}$ values at which, however, the estimation of base bound and of $\mathrm{pH}$ would be attended by such large errors as to make the experimental data unreliable.

Additional evidence for the conclusion that the phenolic hydroxyl groups of tyrosine bind base is provided by the data on the combination of methylated fibroin with potassium hydroxide, given in table 4 . In this material all but approximately one-fifth of the tyrosine had been methylated. The titration curve (solid circles, fig. 1), is shifted toward higher $\mathrm{pH}$. Up to $\mathrm{pH} 9.5$ very little base is bound, and at any given $\mathrm{pH}$ the amount bound is very much less than in the case of the unmethylated fibroin. This greatly decreased base-binding capacity of the methylated fibroin lends support to the interpretation of the very steep portion of the curves for nonmethylated fibroin as being due to the titration of the phenolic hydroxyl groups of tyrosine.

TABLE 4.-Amounts of base bound by methylated fibroin at $O^{\circ} \mathrm{C}$

\begin{tabular}{|r|c|}
\hline $\mathrm{pH}$ & Base bound \\
\hline & $M-q / g$ \\
8.74 & 0.005 \\
9.48 & .005 \\
12.15 & .037 \\
12.55 & .061 \\
12.84 & .091 \\
13.47 & .166 \\
14.14 & .283 \\
\hline
\end{tabular}




\section{REFERENCES}

[1] Speakman and Hirst, Trans. Faraday Soc. 29, 148 (1933).

[2] Lloyd and Bidder, Trans. Faraday Soc. 31, 864 (1935).

[3] Steinhardt and Harris, J. Research NBS 24, 335 (1940) RP1286; Am. Dyestuff Reptr. 29, 103-107, 121-127, 131-134, 147-149 (1940); Textile Research 10, 181-192, 229-252 (1940).

[4] Bergmann and Niemann, J. Biol. Chem 122, 577 (1938).

[5] Rutherford, Patterson, and Harris, J. Research NBS 25, 451 (1940) RP1338; Am. Dyestuff Reptr. 29, 583 (1940); Textile Research 11, 15 (1940).

[6] Rutherford and Harris, J. Research NBS 24, 415 (1940) RP1290; Am. Dyestuff Reptr. 29, 213 (1940); Textile Research 10, 221 (1940).

[7] Lugg, Biochem. J. 31, 1422 (1937).

[8] Viebock and Becker, Ber. deut. chem. Ges. 63B, 3207 (1930).

[9] Sookne, Fugitt, and Steinhardt, J. Research NBS 25, 61 (1940) RP1314; Am. Dyestuff Reptr. 29, 333-336, 355-356 (1940); Textile Research 10, 380 (1940).

[10] Sookne and Harris, J. Research NBS 25, 47 (1940) RP1313; Am. Dyestuff Reptr. 29, 357-360, 383-386 (1940); Textile Research 10, 405 (1940).

[11] Steinhardt, Fugitt, and Harris, J. Research NBS 25, 519 (1940) RP1343.

[12] Schmidt, The Chemistry of the Amino Acids and Proteins, p. 628 (Charles C. Thomas, Springfield, Ill., 1938.)

[13] Vickery and Block, J. Biol. Chem. 93, 105 (1931).

Washington, October 4, 1940. 